\title{
Evaluation of the effect of land use change on runoff using supervised classified satellite data
}

\author{
Samie M. ${ }^{1}$, Ghazavi R. ${ }^{1,}{ }^{*}$, Vali A. ${ }^{1}$ and Pakparvar M. ${ }^{2}$ \\ ${ }^{1}$ Dept. of Watershed Management, Faculty of Natural Resources and Earth Sciences, University of Kashan, Iran \\ ${ }^{2}$ Fars Agricultural and Natural Resources Research and Education Center \\ Received: 17/02/2018, Accepted: 07/03/2019, Available online: 13/03/2019 \\ *to whom all correspondence should be addressed: e-mail: ghazavi@kashanu.ac.ir \\ https://doi.org/10.30955/gnj.002631
}

\section{Abstract}

The main objective of this study was to determine the effect of land use change on runoff in Chenar Rahdar watershed. Land use map of the studied basin was determined using Landsat satellite imagery for 2004 and 2015 using ENVI software. After applying the necessary corrections to the images and field surveys to take the educational points, supervised classification technique and maximum probability algorithm were applied to mapping land use change in the study area. According to results, 6 classes of land use were investigated (bare land, rain fed land, forest land, water agriculture land, rangelands and urban lands). In this study, 21 model parameters were calibrated with monthly runoff using 2004-2012 data and validated using 2012-2015 data. The efficiency coefficient for calibration and validation were between 0.88 and 0.94 , respectively. The land use changes trend within the time interval showed that the highest percentage of incremental changes is related to urban lands with $108.45 \%$, whereas, the highest decline was observed for agricultural land with $12.46 \%$. In order to investigate the effect of land use change on surface runoff, different land use maps were applied to SWAT model, supposing constant condition for other parameters of the model. The results show that surface runoff increased by 11\%, in 2015 compared to 2004. Comprehensive water management can reduce surface runoff in the watershed. The results showed that if all uncertainties were minimized, the calibrated SWAT model can give acceptable runoff simulation results regarding the land use change. These results can be useful for water and environmental resource managers.

Keywords: Land use; rain runoff; SWAT model; Chenar Rahdar.

\section{Introduction}

The hydrologic cycle at the watershed scale is a complex process that affected by climate, the physical characteristics of the watershed (i.e., geology, terrain, soil properties, vegetation), and human activities (i.e., land use practices, reservoir regulations, water transfer project). A number of studies shows that it is insufficient for climate change alone to interpret streamflow trends in some watersheds, while human uses such as land use/cover change especially soil and water conservation can also change hydrological processes and impact the streamflow trends (Liang et al., 2013; Azeb et al., 2018).

To appraise the hydrological and sediment impacts of environmental change, the commonly used methods are the paired catchment approach, statistical analysis, and hydrological modeling. Among these approaches, a hydrological method is an appealing option, since it is the most suitable trend for using as a part of scenario studies (Khoi and Suetsugi, 2014).

The impact of land use changes on runoff is a present topic in hydrologic research and is often assessed by rainfall-runoff model simulation (Naef et al., 2002; Joorabian et al., 2017).

Land use changes have been investigated in Golestan province, northeast of Iran during 2000-2013 using Landsat ETM image (Varamesh et al., 2017). The Results of this study indicate that the main land use change in this study area was the conversion of forest and rangeland to agricultural and residential land uses.

Pikounis et al. (2003) evaluated the hydrological effects of specific land use changes in a catchment of the Pinios watershed in Thessaly, Greece. They examined the effect of land use change using three land use scenarios including complete deforestation and expansion of urban area and expansion of agricultural land, in the Trikala sub-basin. All the three scenarios led to an increased streamflow during the wet season and a decreased during the dry season.

Githui et al. (2009) investigated the impacts of land-cover change on runoff using SWAT model, in Nzoia catchment, Kenya. Land-cover change scenarios namely the worstcase and the best-case scenarios were generated. The results of historical land-cover change indicated the increased area of agricultural from $39.6 \%$ to $64.3 \%$ between 1973 and 2001, while the decreased forest cover from $12.3 \%$ to $7.0 \%$. The land-cover scenarios generated changes in runoff of almost $-16 \%$ and $30 \%$ for the best 
and the worst-case scenarios, respectively, compared to the 1980-1985 runoff.

Phan et al. (2010) studied the effects of land-use change on discharge and sediment yield in the Cau River catchment and reported that the $11.07 \%$ conversion of forest land to agricultural land led to the increased streamflow and sediment load of $3.93 \%$ and $8.94 \%$, respectively.

Ashraf et al. (2014) studied land use change and its impact on watershed hydrology using the SWAT model on Rawal located in the sub Himalayan region. Through the temporal analysis of LANDSAT image data over a $16 \%$ decrease in the scrub forest, coverage was revealed while three-fold increase was found in the built-up land during 1992-2010 periods. The land use changes led to an increase of about $6.0 \%$ in the water yield and $14.3 \%$ in the watershed surface runoff.

Khoi and Suetsugi (2014) using SWAT model evaluated the effects of climate and land-use changes on hydrological processes and sediment yield in the Be River catchment, Vietnam. The results revealed the increased annual flow (by $1.2 \%$ ) and sediment load (by $11.3 \%$ ) caused by deforestation, and the significant increased annual streamflow (by 26.3\%) and sediment load (by $31.7 \%$ ) caused by climate change, as well.

Can et al. (2015) assessed the impacts of different land use scenarios on water budget of Fuhe River, China using SWAT model. The results of hypothetical scenario simulations revealed that increasing the forest land, agriculture land and/or grassland areas and decreasing paddy field and urban areas, surface runoff declined whereas groundwater recharge and evapotranspiration increased.

Anaba et al. (2017) studied the application of SWAT on effects of land use change in the Murchison Bay Catchment in Uganda. The results of runoff and average upland sediment yield estimated from the catchment indicated that both have increased during the study.

Consequently, a better understanding of how land-use changes impact the watershed hydrological processes will attract a crucial interest to plan, manage, and to develop the sustainable water resources (Peter et al., 2017). Although scientists recognized the importance of changes in land use and land cover affecting the water circulation and the spatial-temporal variations in the water resources distribution, the quantitative relation between land use/coverage characteristics and runoff generation or processes is not well-known (Wang et al., 2007; Yasunori et al., 2018).

This study aimed to investigate the effect of land use change on runoff of the Chenar Rahdar watershed using the SWAT model.

\section{Material and methods}

\subsection{Study area}

The study area with a total area of 94959 hectares named Chenar Rahdar watershed is one of the sub-basins of the Maharloo Lake located in the South-East of Shiraz province, in the South Iran (longitude 619911 to 674235; latitude 322,8499 to $32,898,75$ (Figure 1 ). The average temperature of this area is about $6.5^{\circ} \mathrm{C}$ in the warmest month (July), and 28.3 in the coldest month of the year (January). The minimum and maximum absolute temperatures are 14.4 and $43.2^{\circ} \mathrm{C}$ respectively. The length of the dry period is from April to mid-November.

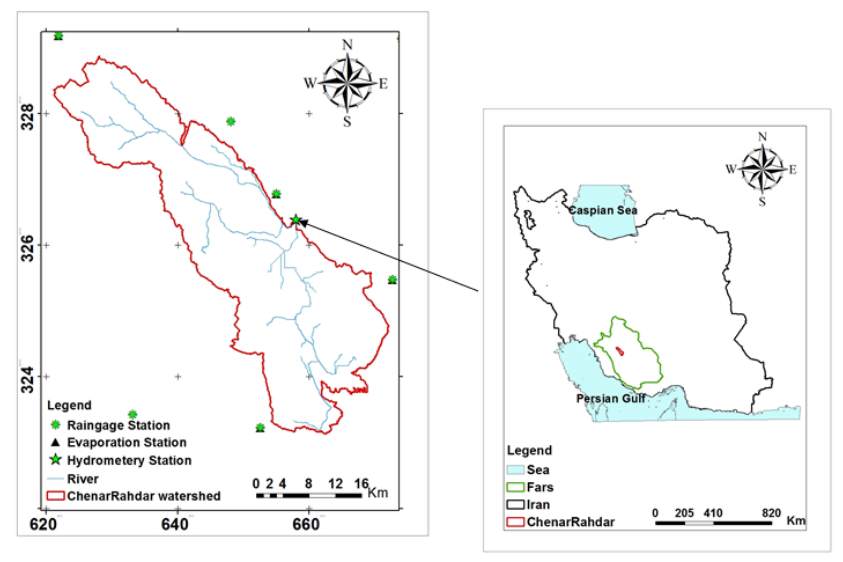

Figure 1. The situation of study area in Iran and Fars province

\subsection{Methodology}

In this study, the SWAT model (version 2012) was used to simulate the effect of land use change on runoff. For this purpose, one year (2003) was chosen as a warm-up period in which SWAT could prime and approach reasonable starting values for the model state variables (Can et al., 2015). Then, the SWAT model was calibrated using measured data from 2004 to 2011 and validated from 2012 to 2015. Then, the effect of land use change on runoff from the basin was simulated using land use maps of 2004 and 2015.

The first step during the calibration process was to determine the most influential model parameters in matching the simulated model results to the observed results. To help achieving this goal, the Automated Sensitivity Analysis tool, LH-OAT (Latin Hypercube Sampling-One at A Time) analysis method was used. This can eliminate some limitations of manual calibration or at least reduce it (Can et al., 2015). For this purpose, Landsat satellite images of April 2004 and 2015 were used.

\subsubsection{Satellite data and their correction}

Educational areas were selected based on the type of land cover using field survey and Google Earth images. The study area was divided into five educational classes. In this way, the land use map was prepared using the spectral properties of various phenomena and educational samples. In this research, the classification accuracy and Kappa coefficient were used to assess the validity of the research. A classification map was obtained after classifying the images using educational samples. Satellite images were falsified and then evaluated for each output to evaluate the accuracy of some samples. 
In this study, ENVI5.3 software was used for satellite data correlation. Geometric correlation was extracted using 1:250000 geographical maps. Radiometric correction (related to the difference in shooting time and the angle of the sun), was doing via radiometric calibration order and the Dn values of the images were converted to radians. In general, electromagnetic waves should affect by the atmosphere via both absorbing and dispersing. The absorption of energy in some electromagnetic spectrum segments is very high and in the other one is too low. In this study, atmospheric correction was done via quick atmospheric correction order in ENVI. The supervised classification method was used to create the land use map. For this purpose, the Maximum Likelihood algorithm was used. This algorithm calculates the average of the data after testing the normality of the data in each class, and then it classifies the class of unclassified pixels into a class belonged to that class as its maximum probability (Lillesand et al., 2004). To evaluate the performance of the model, the statistical criteria such as Nash-Sutcliffe (NSE), Determination coefficient $\left(R^{2}\right)$ and PBIAS were used (Table 2).

\subsubsection{SWAT model parameterization}

Several data layers including land use, soil and topography as well as climate and management information were needed for a SWAT project (Yiannis Panagopoulos et al., 2015). In this study, $10 \mathrm{~m}$ digital elevation model (DEM) was used to characterize slopes, slope lengths and topography map. Land use map that was created by the Iranian natural resources office was used to determine different land use of the study area. The FAO soil map was presented to SWAT model. Daily climate data (2003-2015) was obtained from the Iranian meteorological organization. Hydrometrical data were obtained via water resources management Company (Table 1).

Table 1. Summarized information of the data used in the SWAT model

\begin{tabular}{cccc}
\hline Data & Type & Source & Year and accuracy \\
\hline DEM & Raster & USGS & $10 * 10$ \\
\hline Land use map & Raster & Landsat Image & 2004,2015 \\
\hline Soli map & Raster & FAO & $10 \mathrm{Km}{ }^{*} 10 \mathrm{~km}$ \\
\hline Rain gage & Point & Fars Regional Water Authority (Four stations) & (daily)2003-2015 \\
\hline Temperature & Point & Fars Regional water Authority (Four stations) & (daily)2003-2015 \\
\hline Synoptic & Point & Climatology organization (Shiraz synoptic) & (daily)2003-2015 \\
\hline
\end{tabular}

Table 2. Criteria for the model performance (Me et al., 2015)

\begin{tabular}{|c|c|c|c|c|}
\hline \multirow{2}{*}{ Statistic equation } & \multicolumn{4}{|c|}{ Performance ratings } \\
\hline & Very good & Good & Satisfactory & Unsatisfactory \\
\hline$R^{2}=\frac{\sum_{n=1}^{N}\left(O_{n}-\bar{O}\right)^{2} * \sum_{n=1}^{N}\left(S_{n}-\bar{S}\right)^{2}}{\sum_{n=1}^{N}}$ & $0.7-1$ & $0.6-0.7$ & $0.5-0.6$ & $<0.5$ \\
\hline$N S E=1-\frac{\sum_{n=1}^{N}\left(O_{n}-\bar{O}\right)^{i}}{\sum_{n=1}^{N}} \quad i=2$ & $0.75-1$ & $0.65-0.75$ & $0.5-0.65$ & $<0.5$ \\
\hline$+-P B \mid A S \%=\frac{n=1}{\sum_{n=1}^{N} O_{n}} * 100$ & $<10$ & $10-15$ & $15-25$ & $25<$ \\
\hline
\end{tabular}

On is the nth-observed datum, sn is the nth-simulated datum, $\bar{O}$ is the observed mean value, $\bar{S}$ is the simulated daily mean value, $N$ is the total number of observed data

\section{Result}

3.1. Calibration, validation, sensitivity analysis and uncertainty

In this study, in order to calibrate the data, 21 main parameters affecting runoff (according to research records: Githui et al., 2009; Ashraf, 2014; Khoi and
Suetsugi, 2014; Kiros et al., 2015; Can et al., 2015; Anaba et al., 2017) were used (Table 3). After selecting the parameters, using the monthly average discharge flow data of the PolFasa hydrometric station within 2004-2011, the sensitivity analysis was carried out. The SUFI2 algorithm was run in 3 iterations with 500 times per iteration. The most sensitive parameters used in this study along with their calibrated values are presented in 
Table 3. Totally, the estimated parameter values are physically acceptable. Results from model run during the calibration period (2004-2011) were shown in Figure 2. Then, based on the selected parameters (10 parameters), the model was validated for the 2012-2015 period (Figure 3). The efficiency coefficient (Table 4) in the calibration period was 0.78 , which indicates that the model had a very good performance in simulating the monthly flow. The determination coefficient of 0.82 also indicates the acceptable performance of the model in the simulation of the flow. Moreover, the PBIAS value was equal to $3.6 \%$ during the calibration period, which based on the performance criteria of the model (Me et al., 2015) the previous indices are confirmed (Table 2). The determination coefficient, efficiency coefficient, and PBIAS value in validation period were $0.54,0.43$ and $18.3 \%$, respectively (Table 4 ). In total, the values of all validation indicators indicate the acceptable accuracy of the model in simulating the flow of the Chenar Rahdar watershed. Therefore, the ability of the model to simulate monthly flow in this area is confirmed. Calibrated and validated model were used to evaluate the effects of the land use change and to simulate runoff based on the future land use. The land use map was used as input for 2004 and 2015.

Table 3. The order of sensitivity of the parameters affecting the flow and the default and optimal values in Chenar Rahdar watershed

\begin{tabular}{|c|c|c|c|c|c|c|}
\hline Row & parameter & $\min$ & $\max$ & P-Value & t-Stat & Optima value \\
\hline 1 & $\mathrm{R} \_\mathrm{CN} 2 . \mathrm{mgt}$ & -0.5 & 0.5 & 0.00 & -8.29 & -0.474 \\
\hline 2 & r_SOL_AWC().sol & -0.3 & 0.3 & 0.00 & 7.06 & 0.049 \\
\hline 3 & V__SLSUBBSN.hru & 10 & 150 & 0.00 & 6.92 & 43.377 \\
\hline 4 & r_SOL_K().sol & -0.8 & 0.8 & 0.00 & -3.74 & 0.173 \\
\hline 5 & V__GW_DELAY.gW & 30 & 450 & 0.02 & 2.41 & 238.641 \\
\hline 6 & V__SHALLST.gw & 0 & 1000 & 0.02 & -2.25 & 641.254 \\
\hline 7 & V_EPCO.hru & 0.01 & 1 & 0.10 & 1.64 & 0.699 \\
\hline 8 & V_ALPHA_BF.gw & 0 & 1 & 0.26 & -1.12 & 0.285 \\
\hline 9 & V_GWQMN.gW & 0 & 2 & 0.43 & 0.79 & 1.854 \\
\hline 10 & V_GW_REVAP.gW & 0 & 0.2 & 0.47 & -0.72 & 0.217 \\
\hline 11 & V__MSK_CO1.bsn & 0 & 10 & 0.65 & 0.46 & 1.209 \\
\hline 12 & V__MSK_CO2.bsn & 0 & 10 & 0.72 & -0.36 & 4.181 \\
\hline 13 & r_SOL_BD().sol & -0.3 & 0.3 & 0.74 & -0.33 & 0.330 \\
\hline 14 & V_CH_K2.rte & 5 & 130 & 0.77 & 0.29 & 13.682 \\
\hline 15 & V_OV_N.hru & 0 & 0.8 & 0.81 & -0.25 & 0.359 \\
\hline 16 & V_RCHRG_DP.gw & 0 & 1 & 0.82 & -0.22 & 0.749 \\
\hline 17 & r_SOL_ALB().sol & -0.5 & 0.5 & 0.83 & -0.22 & -0.315 \\
\hline 18 & V_REVAPMN.gW & 0 & 100 & 0.89 & 0.14 & 69.663 \\
\hline 19 & V_ESCO.hru & 0.01 & 1 & 0.91 & -0.12 & 0.099 \\
\hline 20 & V_CH_N2.rte & 0 & 0.3 & 0.91 & 0.11 & 0.197 \\
\hline 21 & V_SURLAG.bsn & 1 & 24 & 0.92 & 0.10 & 10.111 \\
\hline
\end{tabular}

.$v_{-}$: Means the default parameter is replaced by a given value, and $r_{-}$: Means the existing Parameter value multiplied by $(1+a$ given value)

Table 4. Validation and calibration statistics in Chenar Raadar watershed

\begin{tabular}{cccccc}
\hline Period & R-Facor & P-Facor & PBIAS & Efficiency coefficient & Determination coefficient \\
\hline Calibration & 0.97 & 0.65 & 3.6 & 0.78 & 0.82 \\
\hline Validation & 0.93 & 0.52 & 3.18 & 0.68 & 0.74 \\
\hline
\end{tabular}




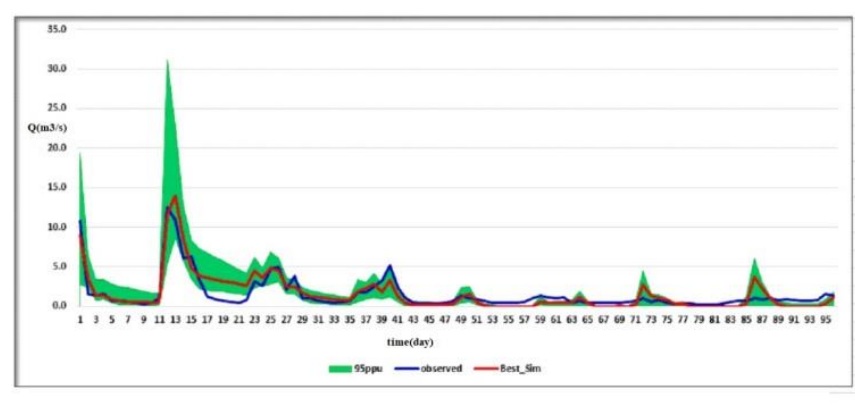

Figure 2. Results from model run during calibration period (2004-2011)

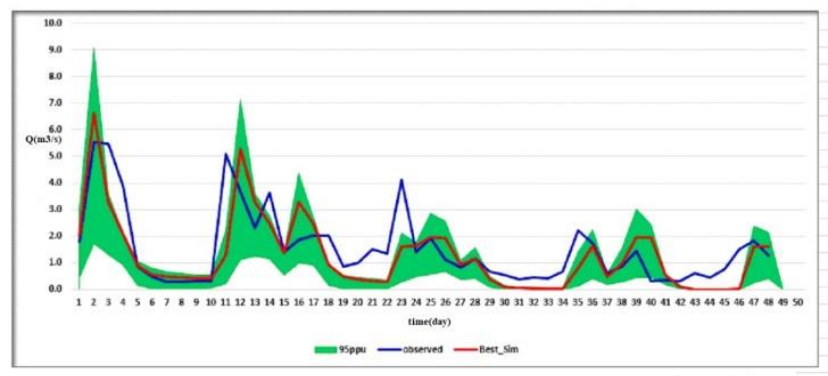

Figure 3. Results from model run during Validation period (20122015)

\subsection{Supervised classification}

In this research, satellite images were classified. In the first step, using false color composite images, especially the composition $(4,3,2)$ in the ENVI software environment, and the investigation of the spectral band histogram, the classes were selected and specified based on differences in properties such as color, tone, texture, shape, and size in the image. Then, with the general recognition of the images and different image processing algorithms, each class was distinct in separate steps using the supervised classification method and the probability maximum likelihood algorithm. Finally, six land use classes (including bare, rain-fed, forest, irrigated, range and urban lands) were distinguished for the studied area.

\subsubsection{Preparation of land use maps and changes trend in 2004 and 2015}

Figure 4 shows the land use map using satellite imagery, in 2004 and 2015, in the Chenar Rahdar watershed, respectively. Based on the Table 5 , the maximum extent of land cover in 2004 was related to rangeland lands with an area of 50868 ha $(53.57 \%$ of the total area). The smallest area covers the 550 ha rain-fed land, which accounts for $0.58 \%$ of the total area. The largest area of land cover in 2015 is about 50449 ha $(53.13 \%$ of the total area) of rangelands. The rain-fed lands with the 551 ha $(0.58 \%$ of the total area) have the smallest area in the study area. While the numerical increase or decrease in the area of land cover in two periods can be a criterion for comparing the trend of land change, using the percentage indicators for increased and decreased findings will always result in a better comparison. In order to investigate the trend of land cover changes in the Chenar Rahdar watershed within 2004 to 2015, the areas extracted from the land cover maps were compared during these periods, and their increase and decrease were compared in terms of hectares and percentages (Table 6). Based on the Table 6 , the highest percentages of incremental changes are for urban lands with $108.45 \%$. Among the declining changes, the highest decline was observed for irrigated farming with $12.46 \%$. Considering that the study area is located in the city of Shiraz, it is concluded that the increase of the urban land by 4372 ha has reduced the irrigated farming surface by 3954 ha and rangelands by 418 ha. One of the reasons for the decline of Irrigated farming can be the reduction of annual precipitation, recent droughts and the reduction of groundwater level in the region. The residential and urban land cover has grown exponentially over the time. This increase has been due to population growth and immigration. Considering the fact that a significant percentage of the area is allocated to rangeland land use, it is necessary to manage the rangeland rehabilitation and restoration and to improve the rangelands. These changes are well illustrated by the effects of human activities in the region.

Having new land use maps in many situations such as natural resource management and planning for land is very important. Hence, timely data on their status plays an essential role in the quality of managing such areas.

\subsection{Simulation the effect of land use change on runoff}

The calibration and validation results showed that the model presented a proper simulation of flow in this basin. Therefore, this model was applied in the range of calibrated parameters for runoff estimation caused by land use changes of the Chenar Rahdar watershed during 2004-2015. The results showed that the annual mean runoff for 2015 (red line) was more than that of 2004(blue line) (Figure 5 and 6).

According to the results, the average monthly runoff was increased in all month when 2015 land used was applied compared to 2004. Maximum monthly discharge was simulated in 2005, whereas, monthly discharged were decreased for both 2004 and 2015 land use after 2005. These results indicate that some other characteristics such as climate change and water supply should affect the amounts of the runoff in this studied watershed.

It is emphasized that running the models, only the land use changed and other climatology information was fixed, thus, it can be concluded that reducing $12 \%$ of irrigated agricultural lands and increasing $108 \%$ of urban land and reducing the amount of rangeland by 418 ha caused an increase of $10.61 \%$ of annual average runoff.

The highest runoff amount associated with summer is about $20 \%$ and the lowest increase is about $7 \%$ in the winter months. Can et al. (2015) stated that vegetation intercepts rainfall, increases the infiltration and decreases the surface runoff. Urbanization results in reduced water quality, increased volume and velocity of runoff, increased incidence and severity of floods, and loss of storage capacity and runoff. Surface runoff carries all other 
components including sediment, nutrient, pesticides, bacteria, agricultural waste, heavy metals, industrial solid and liquid waste affecting the water quality undesirably (Anaba et al., 2017). The increased surface runoff indicates the degraded status in this watershed. It can be concluded that the regional water budget is affected by urban land negatively. Small increases in the urban land are as the strong environmental stressors.

Table 5. Land use classes for the years 2004 and 2015 in the Chenar watershed

\begin{tabular}{ccccc}
\hline \multirow{2}{*}{ Land use } & \multicolumn{2}{c}{2004} & \multicolumn{2}{c}{2015} \\
\cline { 2 - 5 } & Area(ha) & Area (\%) & Area(ha) & Area(ha) \\
\hline Rain fed & 550 & 0.58 & 551 & 0.58 \\
\hline Bare & 1449 & 1.53 & 1449 & 1.53 \\
\hline Forest & 6334 & 6.67 & 6335 & 6.67 \\
\hline Irrigated & 31726 & 33.41 & 27772 & 29.25 \\
\hline Range & 50868 & 53.57 & 50449 & 53.13 \\
\hline URBAN & 4031 & 4.25 & 8403 & 8.85 \\
\hline
\end{tabular}

Therefore, the land use change is effective on runoff by interfering with the amount of water absorption and storage and evapotranspiration, as well as, by changing land use to the other applications and changing the parameters involved during the simulation process. It also affects the runoff.
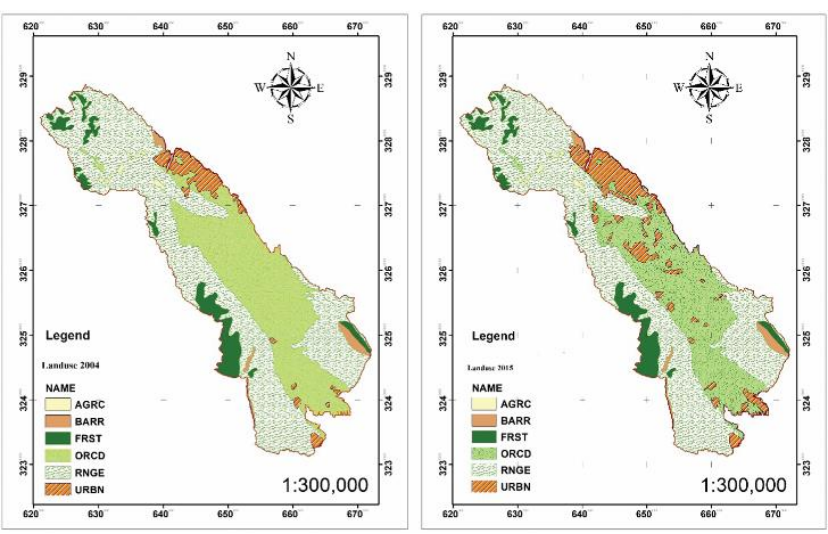

Figure 4. Land use in the Chenar Rahdar watershed in 2004 (right) and 2015 (left)

Krishna et al. (2014) state that plant cover and land use affects the amount of evaporation, groundwater penetration, and surface runoff during and after rainfall.

Table 6. Trend of land use changes during the years 2004 to 2015 in the Chenar Rahed watershed

\begin{tabular}{cccc}
\hline Land use & change type & change Percent & change Rate (ha) \\
\hline Rain fed & Increase & 0.07 & 0.384 \\
\hline Bare & decrease & -0.02 & -0.342 \\
\hline Forest & Increase & 0.02 & 1 \\
\hline Irrigated & decrease & -12.46 & -3954 \\
\hline Range & decrease & -0.82 & -418 \\
\hline Urban & Increase & 108.45 & 4372 \\
\hline
\end{tabular}

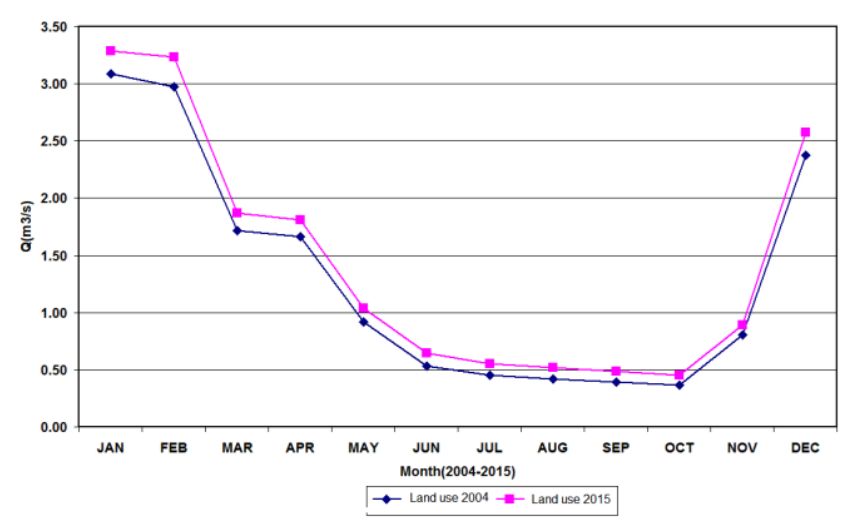

Figure 5. Average Monthly Runoff from 2003 to 2015 in the Chenar Rahdar watershed

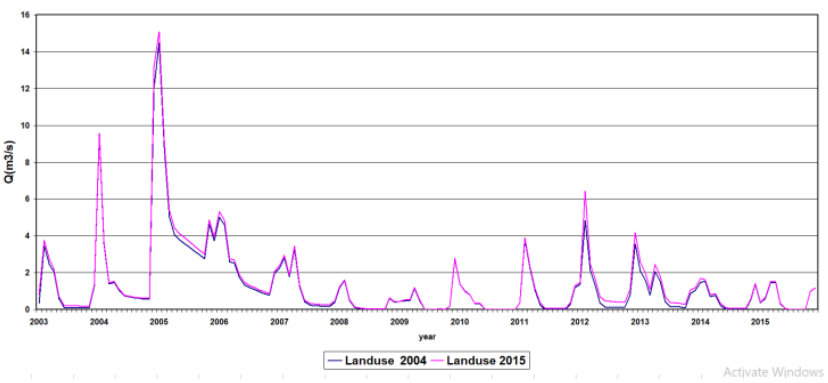

Figure 6. Monthly discharge Hydrograph from 2003 to 2015 in the Chenar Rahdar watershed

According to the results, the maximum increasing change in the study area was urbanization (108.45\%) and maximum decreasing change was related to aquaculture $(-12.46 \%)$. Considering that a part of the study area was located in Shiraz basin, we can conclude that increasing the urban area (4372 ha) cause decreasing in rang and agricultural lands. Also reduction of water level in the study area should be related to the recent climatological drought and groundwater over extraction. Urbanization should reduce the quality of water, increases the volume and speed of runoff, and increases the frequency and severity of floods. Land use change and urbanization should also reduce the storage capacity of soil and runoff coefficient.

\section{Discussion}

The human activities impact on runoff are reflected in land use and land cover changes. Land use change occurs gradually, moreover, the accumulation of impacts on runoff also is a gradual event (Zhan et al., 2014).

Understanding how the land use change affects the river basin hydrology will allow the planners to formulate policies for minimizing the undesirable effects of future land use changes (Mustafa et al., 2005).

In this study, investigation of the land use change process within 2004 to 2015 showed that the highest percentage of incremental changes is related to urban lands with $108.45 \%$. Among the declining changes, the highest decline was observed for irrigated farming with $12.46 \%$. 
In order to investigate the impact of land use change on runoff, SWAT model was used using two land use scenario (2004 and 2015). According to the results of calibration and validation, the model showed a proper simulation of flow in this basin. Moreover, the values of all evaluation indicators represent the acceptable accuracy of the model in simulating the flow of the Chenar Rahdar watershed. Therefore, the ability of the model to simulate monthly flow in this area is confirmed. On the other hand, if all uncertainties are minimized, a well-calibrated SWAT model can generate reasonable hydrologic simulation regarding the land use, which is valuable for water and environmental resources managers and policy and decision makers (Anaba et al., 2017).

Therefore, this model in the range of calibrated parameters for estimating the runoff caused by the land use changes of the Chenar Rahdar watershed was applied during 2004-2015. The results showed that the annual mean runoff for 2015 was more than that in 2004, moreover, they indicated an increase of $10.6 \%$. The results of simulations revealed that urbanization is the strongest contributor to changes in surface runoff. Pikounis et al. (2003); Tang et al. (2005); Nie et al. (2011); Maalim et al. (2013); Can et al. (2015) and Anaba et al. (2017) showed that the increase in urbanization might possibly create impervious layers decreasing the infiltration and percolation of water to the shallow aquifers that lead to increases in surface runoff.

Urbanization can be considered as a potential main environmental stressor that controls the hydrological components (Can et al., 2015). The increase in urban area would result in decreased infiltration caused by surface sealing (Wu et al., 2007). Increases in impervious surfaces result in increased storm-runoff volumes and flood peaks and decreased groundwater recharge and lower stream flows (Dow, 2007).

Land use change by changing canopy interception, soil properties and biophysical factors affecting the evapotranspiration, and groundwater use change, impacts watershed water yield (Zheng et al., 2016).

The study area located in an arid and semiarid area, where in the normal condition, the bimodal and high rainfall should lead to infrequent flood that can be extremely damaging. When such condition combined with land use change and urbanization, negative environmental effects such as soil erosion, damage flood and finally immigration will be occurred. To reduce the negative impacts of urbanization and drought and also to reduce flood damaging in the arid and semiarid areas, a sustainable management system is an essential that keeps water far from evapotranspiration, increases infiltration and decreases flood hazards.

In this paper, it is emphasized that SWAT is a very flexible and strong tool to simulate a variety of land management problems in different catchments with various climatic and land cover conditions. To predict the expected changes in the river flow regime, the model can be used for future land use scenarios. This study will be useful in evaluating a better management option for sustainable land and water resources development in the Chenar Rahdar watershed in the future.

\section{References}

Anaba L.A., Banadda N., Kiggundu N., Wanyama J., Engel B. and Moriasi D. (2017), Application of SWAT to Assess the Effects of Land Use Change in the Murchison Bay Catchment in Uganda. Computational Water, Energy, and Environmental Engineering, 6, 24-40.

Ashraf R.N., Wahab A., Ahmad B., Yasin M. and Saleem M. (2014), Assessment of Landuse Change and Its Impact on Watershed Hydrology Using Remote Sensing and SWAT Modeling Techniques a Case of Rawal Watershed in Pakistan Arshad. International Journal of Agricultural Science and Technology (IJAST), 2(2), 61-68.

Azeb W., Florian Z. and Wolfram M. (2018), Assessing land use and land cover changes and agricultural farmland expansions in Gambella Region, Ethiopia, using Landsat 5 and Sentinel 2a multispectral data. Helyon, 8(4), 1-28.

Can T., Xiaoling C., Jianzhong L., Gassman P.W., Sabine S. and Jose-Miguel S.P. (2015), Assessing impacts of different land use scenarios on water budget of Fuhe River, China using SWAT model. International Journal of Agricultural and Biological Engineering, 8(3), 95-109.

Dow C.L. (2007), Assessing regional landuse/cover influences on New Jersey Pinelands streamflow through hydrograph analysis. Hydrological Processes, 21, 185-197.

Githui F., Mutua F. and Bauwens W. (2009), Estimating the impacts of land-cover change on runoff using the soil and water assessment tool (SWAT): case study of Nzoia catchment, Kenya. Hydrological Sciences Journal, 54(5), 899908.

Joorabian S.S., Kamran S., Gholamalifard M., Azari M., SerranoNotivoli, R and Ignacio López-Moreno J. (2017), Impacts of future land cover and climate change on the water balance in northern Iran. Hydrological Sciences Journal, 2150-3435.

Khoi D.N. and Suetsugi T. (2014), Impact of climate and land-use changes on hydrological processes and sediment yield-a case study of the Be River catchment, Vietnam. Hydrological Sciences Journal, 59(5), 1095-1108.

Kiros G., Shetty A. and Nandagiri L. (2015), Performance Evaluation of SWAT Model for Land Use and Land Cover Changes in Semi-Arid Climatic Conditions: A Review. Hydrology: Current Research, 6(3), 7.

Krishna Hari B., Sai Kumar R., Sampath O. and Nagendher T. (2014), A Review- Impact of land use land cover change and best management practices in a watershed by using swat model. International Journal of Pure \& Applied Bioscience, 2(1), 276-285.

Liang K., Liu C. and Song X. (2013), Impacts of climate variability and human activity on streamflow decrease in a sediment concentrated region in the Middle Yellow River. Stochastic Environmental Research and Risk Assessment, 27, 17411749.

Lillesand T., Kieffer R.W. and Chipman J. (2004), Remote sensing and Image Interpretation, 5th Edition, John Wiley \& Sons, New York, 763 p.

Maalim F.K., Melesse A.M., Belmont P. and Gran K.B. (2013), Modeling the Impact of Land Use Changes on Runoff and 
Sediment Yield in the Le Sueur Watershed, Minnesota Using GeoWEPP. Catena, 107, 35-45.

Me W., Abell J.M. and Hamilton D.P. (2015), Effects of hydrologic conditions on SWAT model performance and parameter sensitivity for a small, mixed land use catchment in New Zealand. Hydrology and Earth System Sciences, 19, 41274147.

Mustafa Y.M., Amin M.S.M., Lee T.S. and Shariff A.R.M. (2005), Evaluation of land development impact on a tropical watershed Hydrology Using Remote Sensing and GIS. Journal of Spatial Hydrology, 5(2), 16-30.

Naef F., Scherrer S. and Weiler M. (2002), A process based assessment of the potential to reduce flood runoff by land use change. Journal of Hydrology, 267, 74-79.

Nie W., Yuan Y., Kepner W., Nash M.S., Jackson M and Erickson C. (2011), Assessing Impacts of Landuse and Landcover Changes on Hydrology for the Upper San Pedro Watershed. Journal of Hydrology, 407, 105-114.

Panagopoulos Y., Gassman P.W., Jha M.K., Kling C.L., Campbell T., Srinivasan R., White M., Arnold J.G. (2015), A refined regional modeling approach for the Corn Belt - Experiences and recommendations for large-scale integrated modeling. Journal of Hydrology, 524, 348-366.

Peter Chibuike C., Alozie M.C., Agbaeze U.O. and Obasi C.E. (2017), Spatio-Temporal Analysis of Land Use Dynamics Using Change Detention Analysis: Case Study of Umuahia Municipal, Abia State. Nigeria. (GIS and Remote Sensing). International Journal of Advanced Research in Science, Engineering and Technology, 4(8), 4454-4464.

Phan D.B., Wu C.C. and Hsieh S.C. (2010), Land-use change effects on discharge and sediment yield of Cau River catchment in Northern Vietnam. in: Kim N.-W. and Srinivasan R., eds. Proceedings of 2010 international SWAT conference, 4-8 August, Seoul, 350-361.

Pikounis M., Varanou E., Baltas E., Dassaklis A. and Mimikou M. (2003), Application of the SWAT model in the Pinios River Basin under different Land use Scenarios. Global Nest: the International Journal, 5, 71-79.

Tang Z., Engel B.A., Pijanowski B.C. and Lim K.J. (2005), Forecasting Land Use Change and Its Environmental Impact at a Watershed Scale. Journal of Environmental Management, 76, 35-45.

Varamesh S., Hosseini S.M. and Rahimzadegan M. (2017), Detection of land use changes in northeastern Iran by landsat satellite data. Applied Ecology and Environmental Research, 15(3), 1443-1454.

Wang G., Liu J., Kubota J. and Chen L. (2007), Effects of land-use changes on hydrological processes in the middle basin of the Heihe River, northwest China. Hydrological Processes, 21, 1370-1382.

Wu W., Hall C.A.S. and Scatena F.N. (2007), Modelling the impact of recent land-cover changes on the stream flows in northeastern Puerto Rico, Hydrological Processes, 21, 29442956.

Yasunori I., Kenichi N., Hiroya Y. and Otsukic S. (2018), Variation and changes in land-use intensities behind nickel mining: Coupling operational and satellite data. Resources, Conservation and Recycling, 134, 361-366.

Zhan C.S., Jiang S.S., Sun F.B., Jia Y.W., Niu C.W. and Yue W.F. (2014), Quantitative contribution of climate change and human activities to runoff changes in the Wei River basin, China. Hydrology and Earth System Sciences, 18, 3069-3077.

Zheng J., Sun G., Li W., Yu X., Zhang C., Gong Y. and Tu L. (2016), Impacts of land use change and climate variations on annual inflow into the Miyun Reservoir, Beijing, China. Hydrology and Earth System Sciences, 20, 1561-1572. 